\title{
INTERNATIONAL JOURNAL OF WILDLAND FIRE
}

\section{publish.csiro.au/wf}
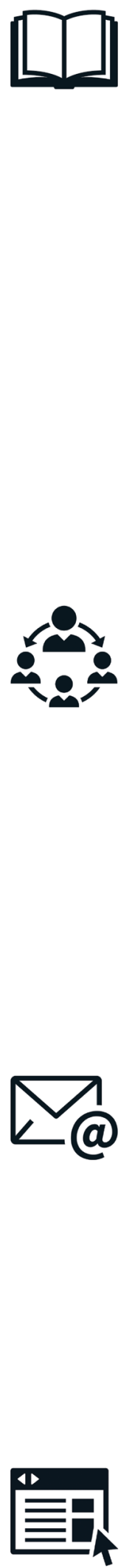

- Prepare: publish.csiro.au/wf/forauthors

- Submit: mc.manuscriptcentral.com/csiro-wf wildland fire will be considered. the globe.

\section{AUTHOR BENEFITS}

- International reach and discoverability

- Indexing in a wide variety of relevant databases

- Professional copyediting for every paper

- Authors retain copyright

- Green Open Access with no embargo

- Gold Open Access compliant with major funders

- Rapid online publication ahead of issue release

\section{STAY IN CONTACT}

- publishing.ijwf@csiro.au \#Int|JWildlandFire

- $\quad$ Sign up for free journals content emails publish.csiro.au/earlyalert

- Recommend the journal to your librarian publish.csiro.au/journals/recommend

\section{SUBMIT YOUR ARTICLE ONLINE}

\section{WiLDLAND FIRE}

at understanding the basic principles of fire as a process, understanding its ecological impact at the stand level and the landscape level, modelling fire and its effects, or presenting information on how to effectively and efficiently manage fire. Manuscripts pertaining to physical and societal aspects of

The journal has an international perspective, since wildland fire plays a major social, economic and ecological role around

- Capture impact through citation tracking and Altmetrics

- Join the conversation on social media using hashtag

C $\mathbf{O} \mid \mathbf{E}$

As a member of the Committee on

Editors-in-Chief:

Susan Conard

George Mason University

Stefan Doerr

Swansea University

Publishing Model: Hybrid

Open Access options available

Frequency: 12 issues/year

Publishing since: 1991

ISSN: 1049-8001 (print + online)

eISSN: 1448-5516 (online)

Published on behalf of:

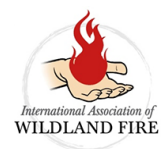

Publication Ethics (COPE), International

Journal of Wildland Fire supports its core

practices and is committed to

transparency in scholarly publishing.

LEARN MORE ABOUT THE

JOURNAL

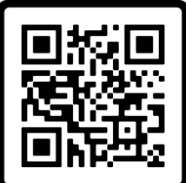

SCAN ME 


\section{JOURNAL METRICS}

\section{SPEED}

70 days from manuscript submission to first decision

24 days from manuscript acceptance to publication

\section{USAGE}

$\mathbf{1 4 1 , 9 5 7}$ downloads in 2021

993 Altmetrics mentions in 2021

\section{REJECTION RATE}

$\mathbf{5 6 \%}$ rejection rate in 2021

\section{IMPACT}

\# Ranking in area

12/69 in Forestry (Q1)

3.4 Impact Factor

3.8 5-Year Impact Factor

TC $\mathbf{6 6 7 4}$ Total Citations in 2021

JCI 1.3 Journal Citation Indicator

cs $\mathbf{5 . 7}$ CiteScore

Highest percentile 91\% (14/153 in Forestry)

SNIP $\quad 1.1$ SNIP

Source Normalised Impact per Paper

SJR $0.9 \mathrm{SJR}$

SCImago Journal Rank

h5 34 h5-index

Google Scholar index for papers published 2017-21

\section{ABOUT CSIRO PUBLISHING}

CSIRO Publishing operates as an editorially independent science publisher within Australia's premier research group, Commonwealth Scientific and Industrial Research Organisation (CSIRO), and has been publishing journals since 1948. Our internationally recognised publishing program includes journals, books and magazines and covers a wide range of scientific disciplines.

\section{PARTNER ORGANISATIONS}

The Association of Society Publishers

Copyright Clearance Center

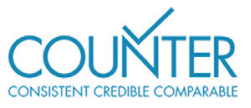

research4 life
Crossref

Altmetric

$\$$ Dimensions

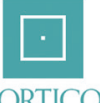

\section{publons}

